Ann. Geophysicae 18, 640-652 (2000) (C) EGS - Springer-Verlag 2000

\title{
CUTLASS HF radar observations of high-latitude azimuthally propagating vortical currents in the nightside ionosphere during magnetospheric substorms
}

\author{
J. A. Wild, T. K. Yeoman \\ Department of Physics and Astronomy, University of Leicester, University Road, Leicester, LE1 7RH, UK \\ E-mail: J.Wild@ion.le.ac.uk
}

Received: 22 December 1999 / Revised: 13 March 2000 / Accepted: 14 March 2000

\begin{abstract}
High-time resolution CUTLASS observations and ground-based magnetometers have been employed to study the occurrence of vortical flow structures propagating through the high-latitude ionosphere during magnetospheric substorms. Fast-moving flow vortices $\left(\sim 800 \mathrm{~m} \mathrm{~s}^{-1}\right)$ associated with Hall currents flowing around upward directed field-aligned currents are frequently observed propagating at high speed $\left(\sim 1 \mathrm{~km} \mathrm{~s}^{-1}\right)$ azimuthally away from the region of the ionosphere associated with the location of the substorm expansion phase onset. Furthermore, a statistical analysis drawn from over $1000 \mathrm{~h}$ of high-time resolution, nightside radar data has enabled the characterisation of the bulk properties of these vortical flow systems. Their occurrence with respect to substorm phase has been investigated and a possible generation mechanism has been suggested.
\end{abstract}

Key words: Ionosphere (auroral ionosphere; electric fields and currents) - Magnetospheric physics (storms and substorms)

\section{Introduction}

The study of highly time-dependent ionospheric electric fields that arise as a result of the substorm process and their coupling with magnetospheric source regions remains an area of lively discussion and debate. Previously, rapid ionospheric flows variations between 50 and $1000 \mathrm{~m} \mathrm{~s}^{-1}$ have been observed within localised electrojet features over the time scale of a few minutes (Morelli et al., 1995) and these flows are usually associated with large increases $(\sim 500 \%)$ in ionospheric conductance. The extended field-of-view and high-time

Correspondence to: J. A. Wild resolution of High Frequency (HF) radars makes them particularly suitable for investigating large-scale ionospheric flow dynamics over short time scales $(\sim 10 \mathrm{~s})$, especially in the regions of high conductivity and low electric field at the location of substorm onset.

Using the Finland radar of the Co-operative UK Twin Located Auroral Sounding System (CUTLASS) in a non-standard high-time resolution mode, Yeoman and Lühr (1997) observed pulses of equatorward flow exceeding $\sim 600 \mathrm{~m} \mathrm{~s}^{-1}$ during the expansion phase of an interval of high-latitude substorm activity. The extent of the enhanced flow regions within the field-of-view of the CUTLASS radar was $400-500 \mathrm{~km}$ in longitude and $300-400 \mathrm{~km}$ in latitude with a duration of $\sim 5 \mathrm{~min}$ and a repetition period of $\sim 8 \mathrm{~min}$. By incorporating the ground magnetic perturbations observed by an extended magnetometer network, the transient features were interpreted as being due to ionospheric current vortices associated with field aligned current pairs propagating azimuthally through the field-of-view of an almost meridionally aligned beam. Both coherent and incoherent scatter radars have been employed previously to study similar propagating vortical ionospheric flows such as auroral $\Omega$-bands in the substorm recovery phase (Lühr and Schlegel, 1994; Wild et al., 1999) and dayside travelling convection vortex events (Lühr et al., 1996) although the relatively short lifetimes of the substorm expansion phase phenomena observed by Yeoman and Lühr (1997) required high-time resolution observations. Subsequently, Yeoman and Wild (1998) identified the bipolar signature of the transient convection features in observations made by the Iceland radar of the CUTLASS system. Here the use of an almost azimuthally pointing beam operating in a high-time resolution mode ( $\sim 14$ s) enabled the authors to more clearly observe the azimuthal motion of a region of intense 1-o-s ionospheric flow velocity $\left(\sim \pm 600 \mathrm{~m} \mathrm{~s}^{-1}\right)$ as it propagated away from the radar in an eastward direction (away from local midnight) at $\sim 800 \mathrm{~m} \mathrm{~s}^{-1}$. Yeoman et al. (1998) used measurements from the Geotail spacecraft to associate the propagating ionospheric convection 
features with a dawnward perturbation and dipolarization of the magnetic field in the postmidnight sector of the geomagnetic tail.

In this work, case studies from two intervals of substorm activity are presented in order to demonstrate the radar signatures of the ionospheric flows that arise due to azimuthally propagating vortical currents (hereafter referred to as APVCs). Measurements from ground magnetometers have also been included in order to study the characteristic perturbations in the local magnetic field. Finally, by performing a statistical study of all available CUTLASS high-time resolution data the relationship between APVC occurrence and substorm phase is examined.

\section{Instrumentation}

Figure 1 presents the geographical distribution of the instrumentation employed in this study. Ionospheric convection velocities are provided by CUTLASS, which comprises a pair of HF coherent radars located at Hankasalmi, Finland and Pykkvibær in Iceland and form part of the international SuperDARN chain (Greenwald et al., 1995). Each radar of the system is frequency agile $(8-20 \mathrm{MHz})$, routinely measuring the line-of-sight (1-o-s) Doppler velocity and spectral width of, and the backscattered power from, ionospheric plasma irregularities. In normal operation the field-ofview (f-o-v) of each radar is formed by scanning sequentially through 16 beams of separation $3.24^{\circ}$, each beam gated into 75 ranges of $45 \mathrm{~km}$ each. Typically, the dwell time on each beam is 3 or $7 \mathrm{~s}$ resulting in a scan of the complete f-o-v covering $52^{\circ}$ in azimuth and over

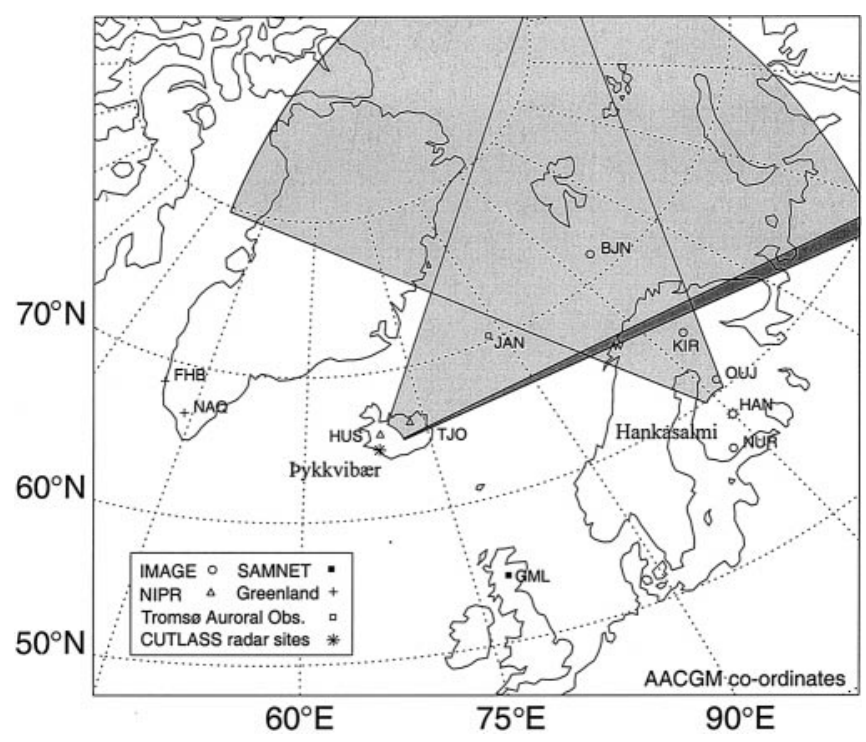

Fig. 1. The location and fields-of-view of the Co-operative UK Twin Located Auroral Sounding System (CUTLASS), beam 15 of the Iceland radar is indicated by dark shading. An AACGM coordinate grid has been overlaid and also displayed are the locations of magnetometer stations from the IMAGE, NIPR, SAMNET, Greenland coastal and Tromso Auroral Observatory arrays as discussed in the text
$3000 \mathrm{~km}$ in range every 1 or $2 \mathrm{~min}$. Common volume data from the two stations can be combined to provide $\mathrm{E}$ and F-region ionospheric convection velocities perpendicular to the magnetic field. The radar system is highly versatile and facilitates the use of non-standard scan modes in order to satisfy the requirements of specific experiments. The high-time resolution measurements required for this study have been made using a technique first employed by Pinnock et al. (1995) in order to study the ionospheric footprint of the cusp. In general, rather than scanning through each beam in the sequence $0,1,2$, $3, \ldots, 15$ the scan pattern is of the form $n, 1, n, 2, n, 3, \ldots$, $n, 15$ allowing measurements to made in beam direction $n$ at an enhanced temporal resolution (6 or $14 \mathrm{~s}$ ) whilst still making observations over the entire $\mathrm{f}-\mathrm{o}-\mathrm{v}$, albeit at a reduced temporal resolution (2 or $4 \mathrm{~min}$ ).

The majority of magnetic field measurements are provided by 3 magnetometer arrays; the Greenland west-coast magnetometer chain (details of the instrumentation and a description of the observatories have been given by Wilhjelm and Friis-Christensen, 1976), the IMAGE magnetometer network (Lühr, 1994) and the SAMNET magnetometer array (Yeoman et al., 1990). In addition the Jan Mayen magnetometer deployed by the Tromsø Auroral Observatory and magnetometers located on Iceland and deployed by the National Institute for Polar Research (Sato et al., 1984) have also been used. All magnetic observations have been made by fluxgate magnetometers and data have been presented in a common co-ordinate system where $X, Y$ and $Z$ components have directions geographic north, geographic east and vertically downwards respectively.

\section{Observations}

\subsection{Interval 1: ground-based magnetometer response}

Figure 2 presents $X$ and $Y$ component magnetograms from a selection of stations of the Greenland coastal, NIPR, IMAGE and SAMNET arrays during the interval 01-04 UT on 27 August, 1996. The lowest panels have been bandpass filtered between 20 and $120 \mathrm{~s}$ in order to display $\mathrm{Pi} 2$ pulsations and provide a reference time for the substorm onsets (Rostoker et al., 1980). Commencing at 01:42 UT NAQ and HUS observed a sudden decrease in the $X$ component $(\leq 100 \mathrm{nT}$ in $\sim 5$ min) whilst GML simultaneously observed Pi2 pulsations which then decayed in amplitude over the following $10 \mathrm{~min}$ indicating the onset of the substorm expansion phase. In general, large-scale disturbances were not observed by high-latitude IMAGE or Greenland magnetometers although low-amplitude, high-frequency oscillations were present. At 01:42 the magnetic local times of NAQ, HUS, OUJ and GML were 23:32, 01:32, 04:06 and 01:12 respectively. A subsequent substorm onset/intensification at 01:53 UT was characterised by a further decrease in $X$ component magnetic field at NAQ and HUS and was accompanied by mid-latitude Pi2 pulsations. This second onset/intensification also imposed no significant perturbations on the 
a.

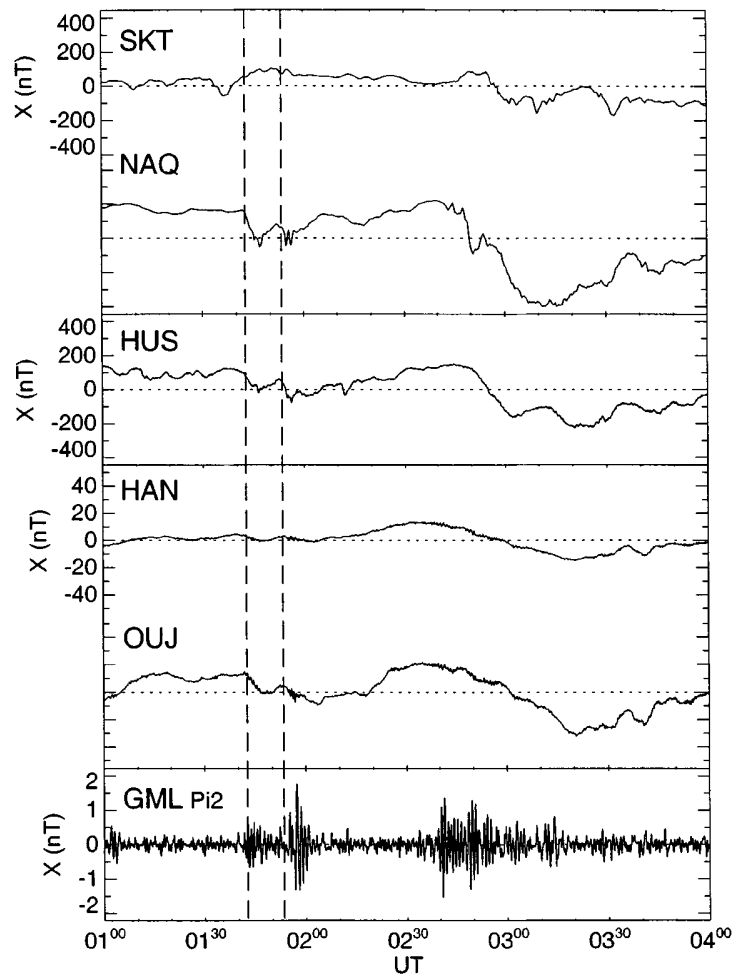

Fig. 2a, b. Ground magnetograms recorded during the interval 01-04 UT on 27 August, 1996, from the Greenland coastal array (top panel), the NIPR Iceland array (second panel), and the IMAGE array (third panel). A bandpass filtered (200-20 s) trace from the GML

magnetic field observed in the high latitude Scandinavian sector (both onsets are indicated in Fig. 2 by dashed vertical lines). For approximately $30 \mathrm{~min}$ after 02:00 UT the $X$ component of the magnetic field appears to recover to a level comparable to that prior to the substorm activity at 01:42 UT. During this interval, at 02:10 UT there is a sharp reduction in the $X$ component measured at HUS. As the $X$ component is going negative the $Y$ component observed at these stations first increases, then decreases and then increases once more before recovering to a pre-disturbance level. No midlatitude $\mathrm{Pi} 2$ pulsations were observed to accompany this activity, the maximum $X$ component disturbance amplitude was $\sim 100 \mathrm{nT}$ and the $Y$ component $\sim 150 \mathrm{nT}$. At 02:40 UT Pi2 pulsations were observed at GML after which $X$ component negative bays began to form first at NAQ and subsequently at HUS and OUL, dominating the remainder of the interval presented.

\subsection{Interval 1: radar measurements of ionospheric convection}

The 1-o-s convection velocities observed by the CUTLASS Iceland radar between 00-04 UT on 27 August, 1996, are presented in Fig. 3a. The near-azimuthal orientation of beam 15 implies that observations are made over a large range of magnetic longitudes $\left(\sim 50^{\circ}\right)$ but a relatively small range of magnetic latitudes $\left(\sim 6^{\circ}\right)$ magnetometer of the SAMNET array is also included (bottom panel). Substorm expansion phase onset/intensifications described in the text are indicated with dashed vertical lines. a $X$ components; b $Y$ components

in comparison to other beams. Line-of-sight Doppler velocities are therefore colour-coded and plotted as a function of universal time and magnetic longitude. During this interval the radar was scanning over half of the possible f-o-v only (beams 8-15), returning to beam 15 every other beam. The dwell time on each beam was $7 \mathrm{~s}$ resulting in a resolution of $14 \mathrm{~s}$ on beam 15 and scan of half of the f-o-v every 2 min. Shortly after the 01:53 UT expansion phase onset/intensification there was a significant reduction in the amount of backscattered signal observed by the radar which remained for $\sim 15$ min. During this period the motion of ionospheric irregularities outside of the reduced scatter region was suppressed (approximately $\pm 100 \mathrm{~m} \mathrm{~s}^{-1}$ ) in comparison

Fig. 3. a Line-of-sight velocities from beam 15 of the CUTLASS Iceland radar as a function of magnetic longitude and time during the interval 00-04 UT on 27 August, 1996. Positive Doppler velocities are towards the radar (approximately westward directed) and negative Doppler velocities are away from the radar (approximately eastward directed). Both of the features discussed in the text are indicated with a dashed line; b Expanded view of the interval 01:30-03:30 UT for magnetic longitudes $65^{\circ}-90^{\circ}$. Overlaid at appropriate magnetic longitudes are longitudinal components of equivalent current vectors derived from ground magnetometer data (see text). The upper panel displays $X$ component magnetic field from TJO, bandpass filtered between $200-20 \mathrm{~s}$ in order to display Pi2 pulsations. In both figures substorm expansion phase onset/intensifications identified from ground magnetometer observations discussed in the text are indicated by solid vertical lines 

Iceland East: vel

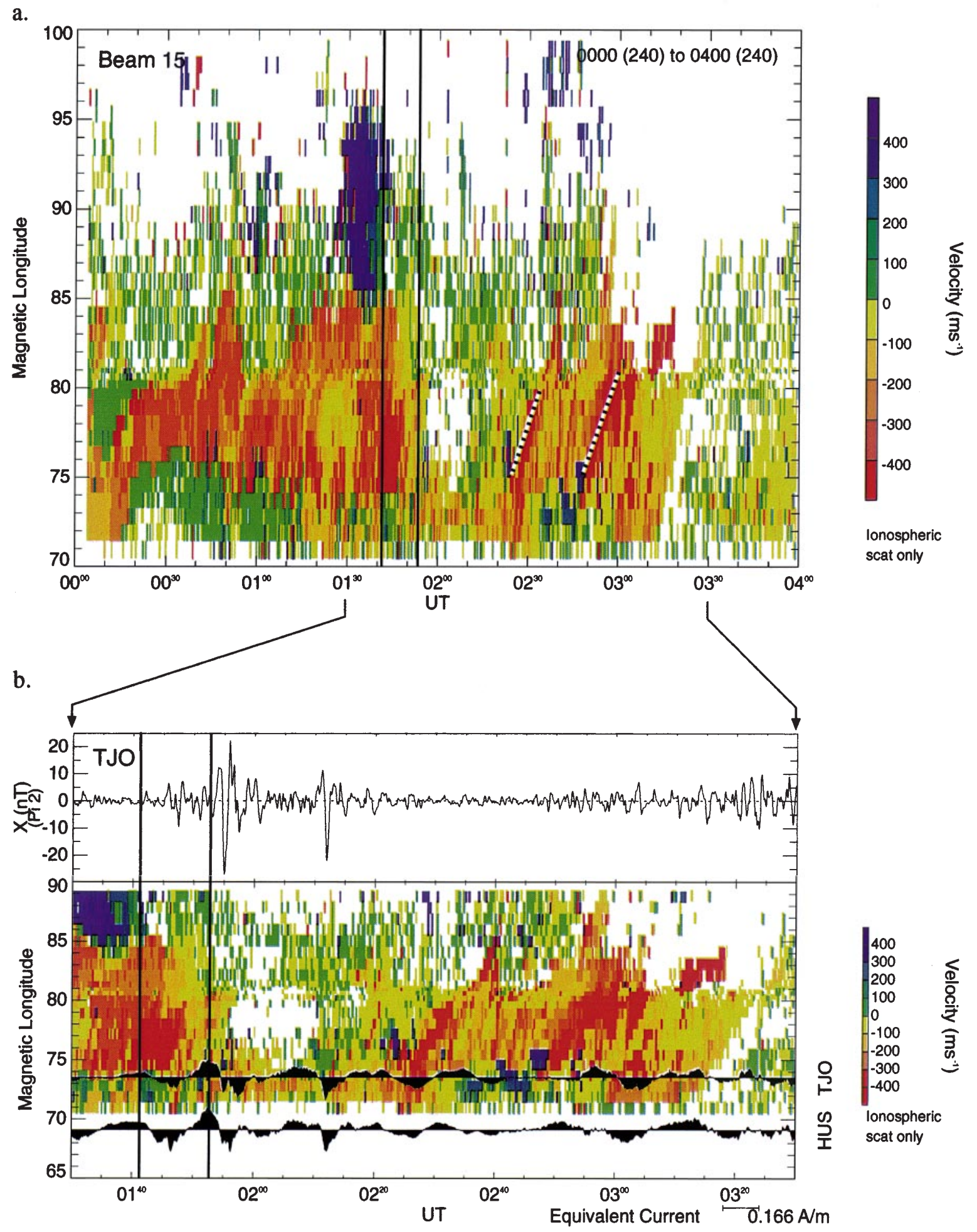

to the flows that occurred prior to substorm onset $\left(\sim \pm 500 \mathrm{~m} \mathrm{~s}^{-1}\right)$. At 02:23 UT a short-lived region of intense flow $\left(\geq 600 \mathrm{~m} \mathrm{~s}^{-1}\right)$ directed toward the radar was observed at $\sim 76.5^{\circ}$ magnetic longitude with a duration $\sim 2 \mathrm{~min}$. This was immediately followed by a region of oppositely directed flow of almost equal magnitude that propagated $\sim 6^{\circ}$ in longitude down-range (i.e. eastward) from the radar over the subsequent $6 \mathrm{~min}$. This is equivalent to an eastward propagation velocity of approximately $850 \mathrm{~m} \mathrm{~s}^{-1}$. At 02:46 UT a similar feature 
was observed: flow initially directed towards the radar (1-o-s velocity $\leq-600 \mathrm{~m} \mathrm{~s}^{-1}$ ) was followed by a region of comparable flow in the opposite direction which then propagates eastward with speed $\sim 1 \mathrm{~km} \mathrm{~s}^{-1}$. The range and elevation angle of the backscattered signals from each feature have been examined, and assuming straight-line propagation the altitudes from which radar returns originated have been estimated. The features are observed in $\mathrm{F}$ region radar backscatter at altitudes of $\sim 150-200 \mathrm{~km}$.

\subsection{Interval 2: ground-based magnetometer response}

Figure 4 presents $X$ and $Y$ component magnetograms from a selection of stations of the Greenland coastal, NIPR, IMAGE and SAMNET arrays during the interval 19-24 UT on 1 July, 1998. During the interval the mid-latitude IMAGE magnetometer station at NUR observed only one significant Pi2 pulsation packet, occurring at 19:54 UT. The magnetic local times of NAQ, TJO, KIR and NUR at 19:54 UT are 17:44, 19:44, 22:04 and 22:04 respectively. Mainland Scandinavia magnetometers of the IMAGE chain (KIR only shown) observed Pi2 oscillations in the $X$ component with magnitude $\sim 50 \mathrm{nT}$ before beginning a steady decrease in amplitude until 20:18 UT. A subsequent intensification at a higher latitude or a poleward expansion then gives rise to an $X$ component negative bay at IMAGE magnetometers located poleward of the Scandinavian mainland (only BJN shown). When filtered appropriately, $X$ component magnetograms from the most poleward mainland stations observe $\mathrm{Pi} 2$ pulsations simultaneously with this onset/intensification. Although disturbed slightly, both $X$ and $Y$ components measured by IMAGE magnetometers subsequently recovered over the next $3 \mathrm{~h}$ to values comparable to those observed prior to the 19:55 UT onset. Magnetometers located in the Greenland and Iceland sectors observed a weak response to these substorm onset/ intensifications although these were confined to the lower latitude stations presented in Fig. 4.

At 20:58 UT, and later at 21:16 UT, increased activity and $\mathrm{Pi} 2$ pulsations (not shown) observed by Iceland sector and Jan Mayen (JAN) magnetometers indicate further substorm activity, this time centred further west than the earlier events. As this interval concludes both the $X$ and $Y$ magnetic field components become more quiescent.

\subsection{Interval 2: radar measurements of ionospheric convection}

During the interval 1900-2400 UT on 1 July, 1998, the ionospheric l-o-s flow velocities observed by beam 15 of the CUTLASS Iceland radar were predominantly directed east-to-west (Fig. 5a). Throughout the interval a.

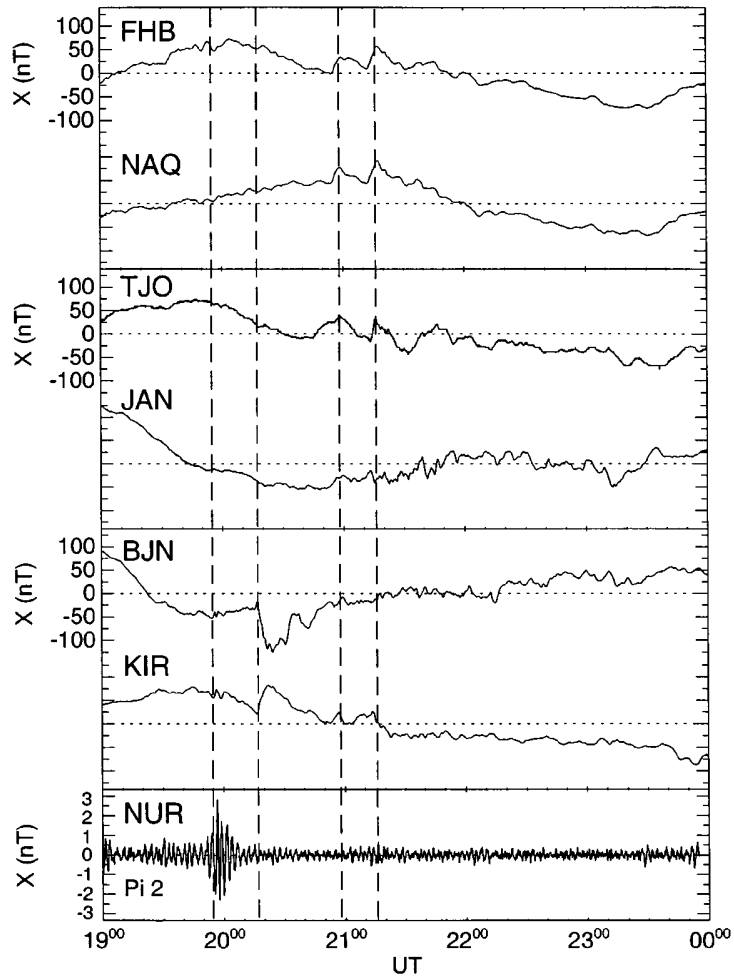

Fig. 4a, b. Ground magnetograms from the Greenland coastal array (top panel), the Jan Mayen and NIPR Tjornes magnetometers (second panel), and the IMAGE array (third panel) for the interval 19-00 UT on 1 July, 1998. A bandpass filtered (200-20 s) trace from

b.

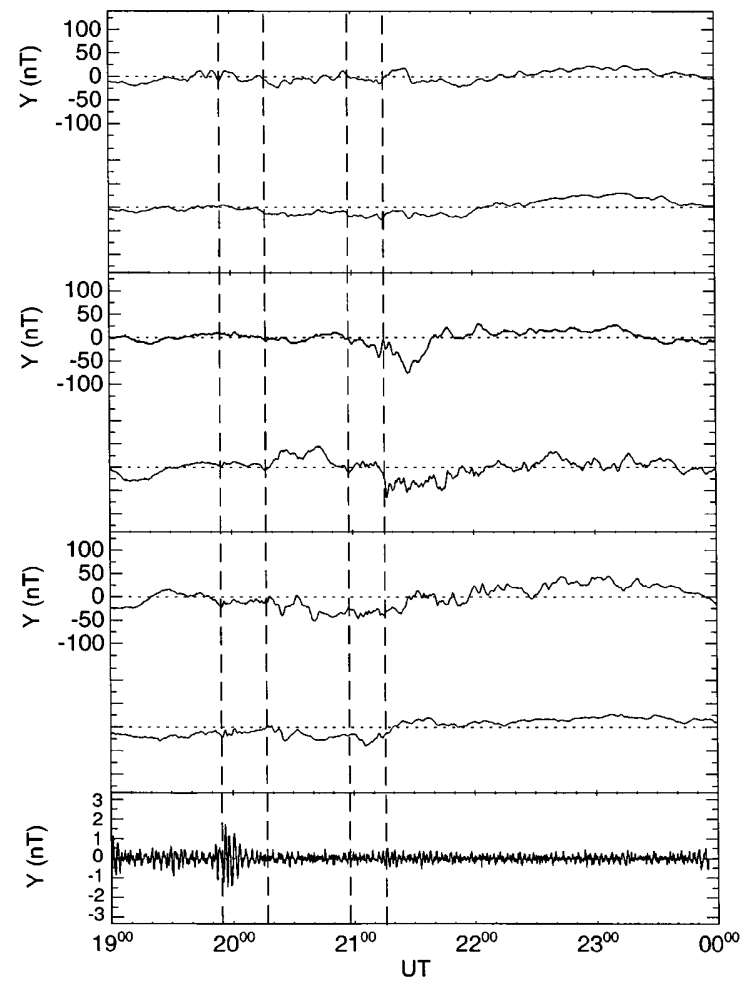

the NUR magnetometer of the IMAGE array is also included (bottom panel). The substorm expansion phase onsets described in the text are indicated with dashed vertical lines. a $X$ components; b $Y$ components 


\section{SUPERDARN PARAMETER PLOT}

\section{Iceland East: vel}

a.

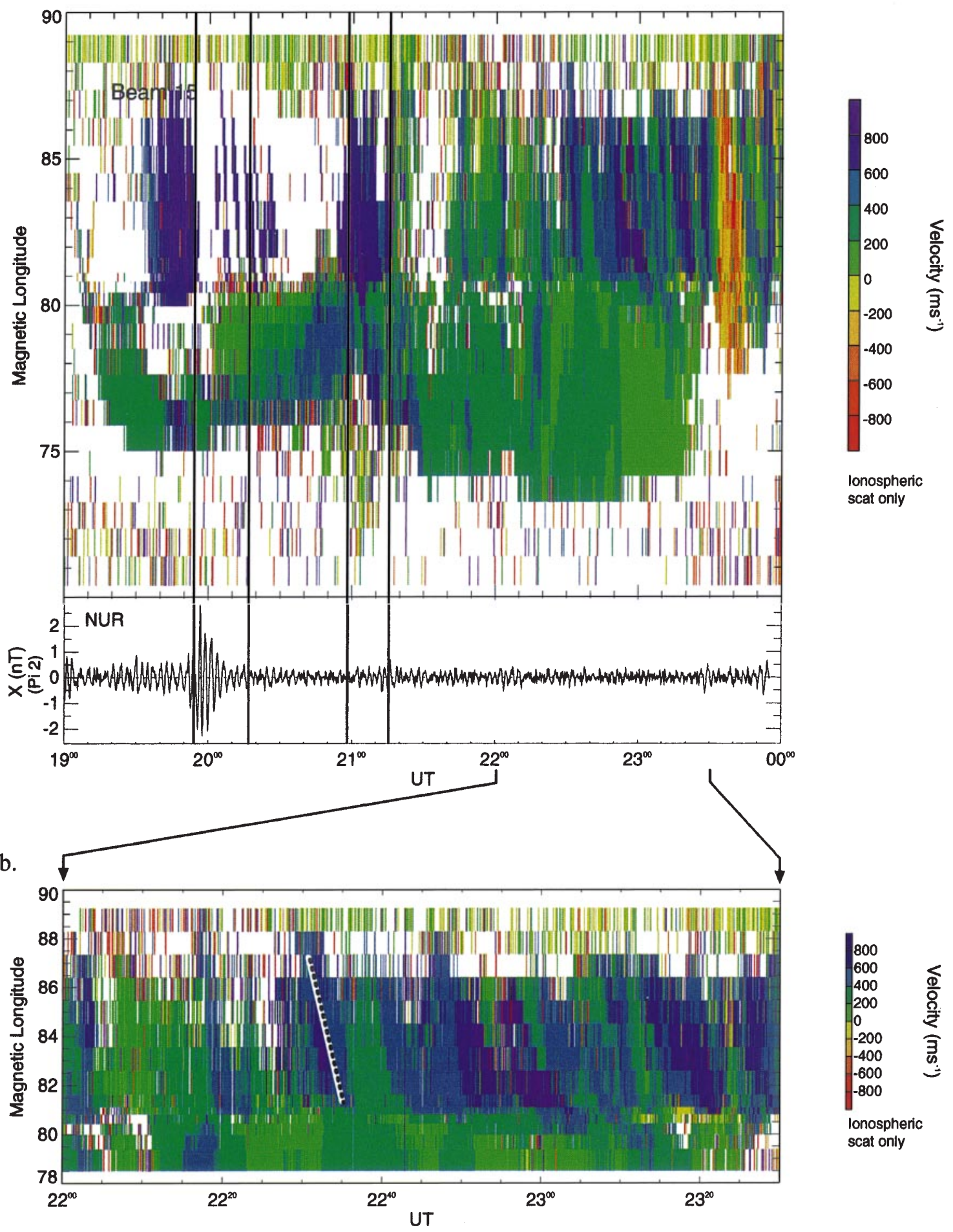

Fig. 5. a Line-of-sight velocities from beam 15 of the CUTLASS Iceland radar as a function of magnetic longitude and time during the interval 19-24 UT on 1 July, 1998. The lower panel contains magnetic field $X$ component data recorded at NUR and bandpass filtered between $200-20 \mathrm{~s}$ in order to present $\mathrm{Pi} 2$ pulsations; $\mathbf{b}$ expanded view of the interval 22:00-23:30 UT for magnetic longitudes $78^{\circ}-90^{\circ}$. For clarity, the propagating vortical current feature first observed at 22:30 $\mathrm{UT}$ is highlighted with a dashed line. In both figures substorm expansion phase onset/intensifications identified from ground magnetometer observations discussed in the text are indicated by solid vertical lines 
presented, the radar was operating in a high-time resolution mode returning to beam 15 every other beam and dwelling for $2 \mathrm{~s}$ on each beam. An area of backscatter with 1-o-s flow velocity $\sim 1000 \mathrm{~m} \mathrm{~s}^{-1}$ extending over magnetic latitudes $81^{\circ}-86^{\circ}$ was observed for $\sim 25 \mathrm{~min}$ prior to the onset at 19:54 UT. This is interpreted as a region of enhanced electric field associated with the expanding auroral oval as it moves into the radar beam. At onset, the backscattered signal diminished rapidly and for approximately $100 \mathrm{~min}$ after the onset the backscattered signal from the range of longitudes between $81^{\circ}-86^{\circ}$ remained substantially reduced except for the interval associated with the later onset/intensifications (20:55-21:15 UT) when flows $\sim 1000 \mathrm{~m} \mathrm{~s}^{-1}$ were once again observed. After 21:40 UT ionospheric backscatter was observed out to magnetic longitudes $\sim 86^{\circ}$ until the end of the interval. At 22:30 UT, a region of flow whose 1-o-s velocity component is directed towards the radar $\left(\sim 1000 \mathrm{~m} \mathrm{~s}^{-1}\right)$ began to propagate from east-to-west, spanning magnetic longitudes $\sim 88^{\circ}-81^{\circ}$ in approximately $7 \mathrm{~min}$, equivalent to a propagation velocity $\sim 800 \mathrm{~m} \mathrm{~s}^{-1}$ (this propagating region is highlighted by a dashed line in Fig. 5b). During the following hour, similar regions of intense flow $\left(\sim 1000 \mathrm{~m} \mathrm{~s}^{-1}\right)$ directed towards the radar and propagating in a roughly east-to-west direction at $\sim 600 \mathrm{~m} \mathrm{~s}^{-1}$ are observed at 22:47, 22:56, 23:12 and 23:26 UT.

\section{Discussion}

The observations during the intervals presented occur in both the pre and post-midnight sectors and in both cases the observed structures propagate azimuthally away from local midnight. Furthermore, in general westward propagating structures in the pre-midnight sector contain westward-directed flow and eastward propagating structures in the post-midnight sector contain eastwarddirected flow. During interval 1 the features were first observed at similar MLTs as the onset region before propagating eastward. The longitudinal separation between the observed APVC and the onset region during interval 2 was larger and there was a greater delay between the first indicators of substorm activity and the radar observations of vortical flows. As a consequence, the causal relationship between individual substorm onsets and observed APVCs during interval 2 is difficult to determine. In order to characterise APVC structure and investigate the relationship to substorms more fully, observations drawn from approximately $1000 \mathrm{~h}$ of high-time resolution, nightside radar measurements have been employed to perform a statistical analysis of APVC behaviour.

\subsection{Interval 1 (27 August, 1996)}

By comparing the $X$ and $Y$ components of the magnetic field at the time of onset and decay of $\mathrm{Pi} 2$ pulsations at a number of longitudinally separated magnetometer stations Lester et al. (1984) were able to determine the location of a simple substorm current wedge system. By applying this technique to the magnetometers employed in this study with coverage $\sim 5 \mathrm{~h}$ of magnetic local time, the substorm onset/intensifications at 01:42 UT and 01:53 UT have been associated with substorm electrojets occurring at a magnetic longitude of approximately $\sim 70^{\circ}$ (i.e. the Iceland/Greenland sector). This implies the magnetic local time of the onsets were $\sim 01: 37$ MLT and $\sim 01: 48$ MLT respectively.

An expanded plot of a subset of ionospheric 1-o-s velocities from interval 1 is presented in Fig. 3b. The region of reduced backscatter that extends over $\sim 6^{\circ}$ of magnetic longitude between 01:56 UT and 02:12 UT is a result of absorption of the radar signal in the ionospheric $\mathrm{D}$ region due to energetic particle precipitation during the substorm expansion phase onset (e.g. Milan et al., 1996). In general, significant HF absorption losses occur when substorm events are located sufficiently close to the instrumentation that large auroral zone electrojet perturbations are observed at ground magnetometer stations in close proximity. The observation of this absorption region complements the interpretation of the substorm onset/intensifications and supports the approximate location and timing determined from ground magnetometer measurements.

The bipolar flow first observed at 02:23 UT is a characteristic signature of the azimuthal propagation by a vortical flow structure through the field-of-view of an almost azimuthally pointing radar beam (Yeoman and Wild, 1998). Figure 6a presents a schematic diagram of such a configuration. An upward aligned ionospheric field aligned current (FAC) system (i.e. downward precipitating electrons) will give rise to vortical Hall currents flowing around the field-line and these Hall currents are manifested as variations in the ionospheric flow observed by the radar. As the flow vortex moves in the beam, the 1-o-s velocity component is first directed toward the radar (colour-coded blue in Fig. 3). Continued propagation through the beam causes the observed 1-o-s velocity component to reverse direction (colourcoded red in Fig. 3). If the propagation path of the APVC is approximately aligned with the radar beam then this flow region may be observed to move downrange from the radar over time, as is the case in the interval presented in Fig. 3. An APVC structure with similar structure is observed at 02:46 UT. Both APVCs were characterised by peak ionospheric flows of approximately $\pm 600 \mathrm{~m} \mathrm{~s}^{-1}$, eastward propagation speed of $\sim 850 \mathrm{~m} \mathrm{~s}^{-1}$ and were observable within the f-o$\mathrm{v}$ of the radar for $\sim 10 \mathrm{~min}$. A schematic representation of the ionospheric 1-o-s flow velocity observations resulting from the passage of a twin-vortex APVC system through a meridional pointing radar beam as discussed by Yeoman and Lühr (1997) is presented in Fig. 6b. In this configuration, background flows are modified as regions of high equatorward flow velocity located between two counter-rotating vortices pass through the radar beam.

In order to study the current structures analogous to those discussed by Yeoman and Lühr (1997) it is necessary to derive a sequence of equivalent current vectors from each of the NIPR magnetometers located 
a.

ICELAND

Eastward propagating current system

traversing a near-azimuthal radar beam
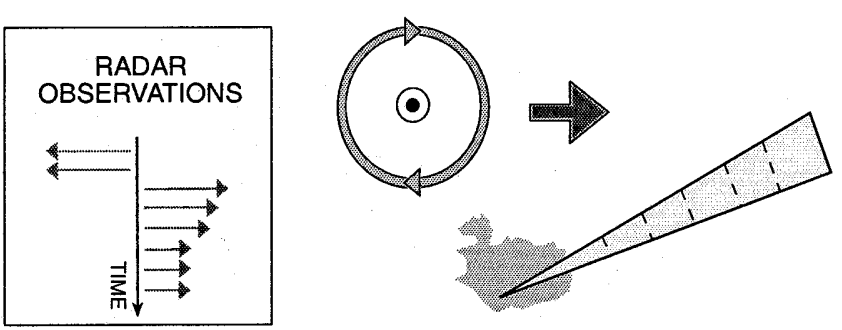

b.

FINLAND

Eastward propagating current system traversing a near-meridional radar beam

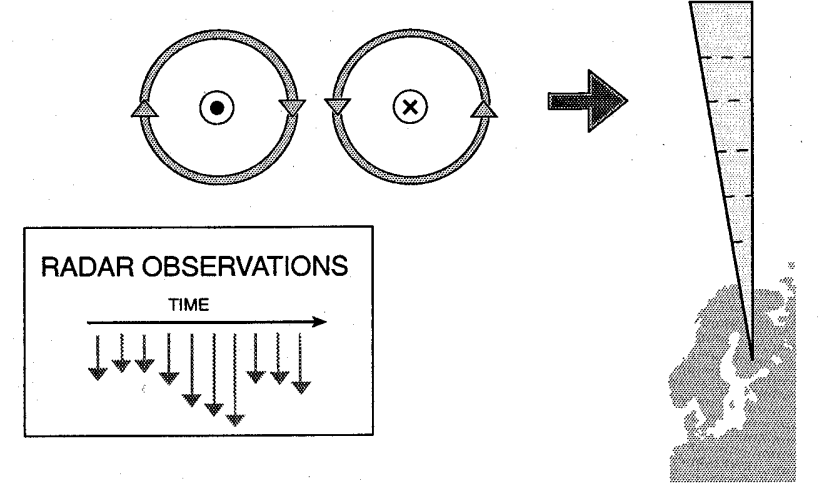

Fig. 6a, b. A schematic interpretation of observed 1-o-s ionospheric flow velocities that result from the passage of vortical flows due to Hall currents circulating around field aligned currents through the f-o-v of $\mathbf{a}$ an azimuthally pointing beam $\mathbf{a}$ and $\mathbf{b}$ a meridionally pointing beam

in Iceland. For an E-region current system with a spatial extent of greater than the E-region height, and assuming a horizontally uniform ionospheric conductivity, then the ground magnetic field deflections, $\mathbf{b}$, can be related to an ionospheric equivalent current density, $\mathbf{J}$, by

$J_{x}=-\frac{2}{\mu_{0}} b_{y} \quad J_{y}=\frac{2}{\mu_{0}} b_{x}$

where $x$ and $y$ indicate the northward and eastward components respectively (Lühr and Schlegel, 1994). For clarity, the east/west, $J_{y}$, component only of the derived equivalent currents is overlaid on the longitude-timevelocity plot of Fig. $3 \mathrm{~b}$ ( + ve $J_{y}$ aligned up the page). However, as the APVC has been observed to propagate eastward $\sim 6^{\circ}$ in magnetic longitude at $\sim 850 \mathrm{~m} \mathrm{~s}^{-1}$, the current vectors have to be plotted against an inverted time scale to give a correct image of the spatial current distribution (see e.g. Lühr and Schlegel, 1994) and these are presented as a function of magnetic latitude in Fig. 7 ( + ve $J_{x}$, aligned up the page, + ve $J_{y}$ aligned to the right). The longitudinal distribution of the various observations necessitates the inclusion of time offsets
NIPR Iceland Magnetometers Equivalent Current

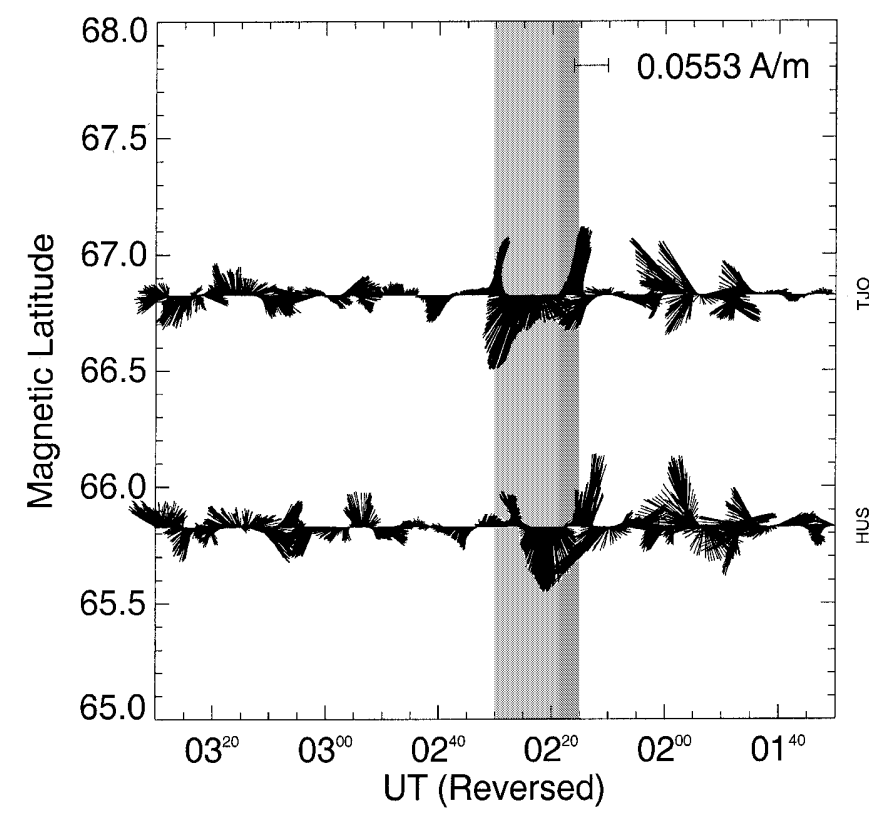

Fig. 7. Equivalent current pattern for the interval 01:30-03:30 on 27 August, 1996, deduced from NIPR magnetometer data from stations located in Iceland. The current vectors have been plotted versus an inverted time axis and time offsets included to account for the longitudinal separation of each magnetometer from the radar. This is appropriate for visualising eastward current features. A current vector pointing vertically up the page represents a current pointing towards the pole. The interval associated with the bipolar 1-o-s Doppler velocity signature described in the text is shaded

in the equivalent current data in order that the azimuthal motion of the APVCs is correctly taken into account. A feature propagating eastward with azimuthal velocity $\sim 850 \mathrm{~m} \mathrm{~s}^{-1}$ will be observed at HUS $\sim 460 \mathrm{~s}$ before entering beam 15 of the Iceland radar and at TJO $\sim 230 \mathrm{~s}$ before arriving in beam 15 . These offsets have been applied in Fig. 7 to allow direct comparisons between the APVC current signatures observed at the two locations. Furthermore, the longitudinal components of these offset equivalent currents have been overlaid on the longitude-time-velocity panel of Fig. 3b so that comparisons of equivalent current and 1-o-s velocity observations can be made. Although highly dynamic throughout the interval, during the period 02:15-02:30 UT there is a clear intensification in the equivalent current strength. At both stations the equivalent current orients poleward at $\sim 02: 15$ UT and rotates through the southward direction in a clockwise sense before returning briefly to a northward pointing at $\sim 02: 30$ UT. The equivalent current strength throughout this rotation is strongest during the initial northward pointing and subsequent southward pointing at which time the magnitudes are approximately equal $(\sim 0.1 \mathrm{~A} / \mathrm{m})$. The magnitude of the derived equivalent currents during the final northward pointing is reduced in both cases by $\sim 30-50 \%$ when compared to the previous north/south maxima and is significantly shorter 
in duration. The first north-south rotation is consistent with variations in current direction due to a timestationary vortical Hall current system flowing in an anticlockwise direction around an upward aligned FAC propagating past the magnetometer. Additional equivalent current signatures to the classic north-south-north rotation are evident, for example the initial south-west orientation of the current vector that arises due to the additional structure apparent at 02:12 in the time-series magnetogram for HUS presented in Fig. 3b. These are possibly indicators of further, less defined current vortices that are present during this interval. The consistency of derived equivalent currents and l-o-s flow velocity data as shown in Fig. 3b during the passage of the main feature (02:15-02:30 UT) supports the interpretation of a significant vortical Hall current system flowing around and upward FAC. In this figure, no time offsets have been included implying that equivalent currents derived from locations westward of the radar will lead radar observations by the calculated offsets described. Westward-directed ionospheric flows (towards the radar, colour-coded blue), are associated with eastward directed currents (pointing up the page) and vice versa. It is possible that the subsequent south-north rotation of the currents could be associated with a downward FAC propagating behind the upward FAC (as suggested in Fig. 6b) but this region of downward FAC is less well defined in its magnetic signature. Also, there is no evidence in the 1-o-s velocity observations of a second counter-rotating flow vortex immediately after the passage of the upward FAC. The bipolar 1-o-s velocity signature observed by the radar at 02:46 UT appears not to have any significant associated equivalent current signature. Radar observations of this feature first occur at a magnetic longitude of $71^{\circ}$ and appear to extend slightly further east that the previous APVC. It is therefore conceivable that this particular APVC system occurred far enough eastwards within the f-o-v of the radar that its influence within the region of coverage of the magnetometers presented was negligible.

An indication of the 2-D structure of the APVC can be obtained from the 8-beam scan of the Pykkvibær radar. Figure 8 presents a spatial distribution of 1-o-s Doppler velocities derived from such a scan which encompasses half of the f-o-v. The high-time resolution beam (beam 15) is located on the extreme right of the $\mathrm{f}-\mathrm{o}-\mathrm{v}$ when viewed from the radar and is sampled every other beam as discussed previously (14 $\mathrm{s}$ resolution). This scan effectively illustrates the bipolar 1-o-s velocity signature of the proposed APVC structure that has been overlaid. Unfortunately, the radar scan mode employed during this interval yielded such a half f-o-v scan only once every $2 \mathrm{~min}$, therefore limiting the possibility of making detailed observations of the APVC as it propagated azimuthally through the f-o-v. By studying a sequence of such plots, however, the spatial scale size of the APVCs observed during interval 1 can be estimated to be $\sim 400 \mathrm{~km}$ in both the latitudinal and longitudinal directions.

The ionospheric signatures of substorms are most commonly observed around local magnetic midnight

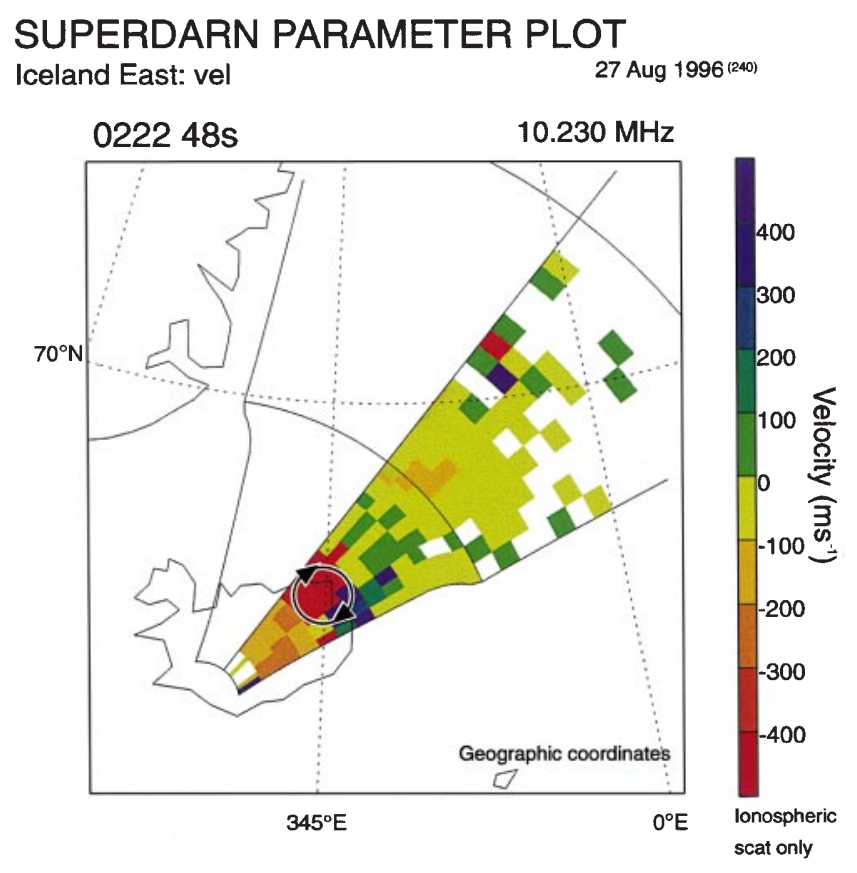

Fig. 8. A scan of half of the f-o-v of the CUTLASS Iceland radar obtained at 02:22:48 UT on 27 August, 1996. The expected vortical flows due to Hall currents flowing around an upward FAC are indicated. Such a flow at the location shown is consistent with the 1-o-s Doppler velocities measured by the radar

whereas during this interval the signatures are located further dawnward at $\sim 01: 37$ MLT and $~ 01: 48$ MLT. The mean MLT of substorms occurring during this study is $\sim 24$ MLT with individual substorms observed over the range 22-02 MLT. The particular MLT of the substorm onsets during this interval are therefore not interpreted as being significant to the occurrence of APVCs.

\subsection{Interval 2 (1 July, 1998)}

Using the technique described the longitudes of the substorm onset/intensifications identified from ground magnetometer observations during the interval 19:5421:16 UT have been determined to be approximately $100^{\circ} \pm 10^{\circ}$. Once again, shortly after the onsets ( $\sim 10 \mathrm{~min})$ the regions from which the backscattered signals are received by the radar are significantly reduced. This is consistent with the expansion of the onset/intensification region and the associated energetic particle precipitation into the $\mathrm{f}-\mathrm{O}-\mathrm{v}$ of the radar resulting in the absorption of the radar signal within the ionospheric D region (Milan et al., 1996).

At 22:30 UT (approximately $75 \mathrm{~min}$ after the final onset/intensification) an APVC was observed to propagate over longitudes $88^{\circ}-81^{\circ}$ over a period of $\sim 7 \mathrm{~min}$, equivalent to a westward propagation speed of $\sim 800 \mathrm{~m} \mathrm{~s}^{-1}$. Within this region of flow a peak 1-o-s ionospheric flow velocity of $\sim 1200 \mathrm{~m} \mathrm{~s}^{-1}$ directed towards the radar was observed. For clarity, the motion of this APVC has been indicated in Fig. 5b by a dashed 
line. During the interval presented in Fig. $5 \mathrm{~b}$ four subsequent APVC systems are observed to propagate from east to west and these are detailed in Table 1. The spatial scales of the APVC systems observed during this interval have been determined by studying the reducedtime resolution scans over all beams in use (in this case 16). All the APVCs were of comparable dimensions being of the order $400 \mathrm{~km}$ in the latitudinal direction and $500 \mathrm{~km}$ in the longitudinal direction and the lifetimes of these events within the $\mathrm{f}-\mathrm{o}-\mathrm{v}$ of the radar varies between 6 and $10 \mathrm{~min}$. Clearly, both the spatial scales and lifetimes of the APVCs in interval 2 are consistent with those observed during interval 1 . However, in contrast to the vortices observed during interval 1 , there are no clear bipolar signatures associated with each APVC system as it propagates through the radar beam. During the interval presented in figure $5 \mathrm{~b}$ there are significant background flows $\geq 400 \mathrm{~m} \mathrm{~s}^{-1}$ in the westward direction in the region through which the APVCs are observed to pass. Assuming an L-shell aligned background flow of $400 \mathrm{~m} \mathrm{~s}^{-1}$, the vortical features in the data may be highlighted by subtracting the component of this velocity in the radar look direction for each beam and range. Using this technique (data not shown) it is possible to identify regions of suppressed westward flows located poleward of the enhanced westward flows presented in Fig. 5. It has therefore been concluded that although a bipolar signature is not observed, the suppression and enhancement of the background flow is consistent with a vortical flow imposed upon a strong background. Furthermore, the location of the suppressed westward flow poleward of the enhanced westward flow is consistent with the clockwise vortical flow pattern associated with an upward FAC.

During this interval no significant vortical currents were revealed by ionospheric equivalent currents derived from ground magnetometer records. Radar observations place the observed features at magnetic latitudes $\sim 68^{\circ}$ and propagating westward from magnetic longitudes $\sim 88^{\circ}-81^{\circ}$, a region that is poorly covered by ground magnetometer stations (see Fig. 1). It is concluded that by the time they were expected to have arrived at the NIPR Iceland magnetometers the APVCs had dwindled to such extent that no significant perturbations to the derived ionospheric equivalent current were observed.

Table 1. Longitudinal extent, azimuthal propagation speed and peak ionospheric 1-o-s velocities for APVC events observed by the CUTLASS Iceland radar during the interval 22:00-23:30 UT on 1 July, 1998 (as shown in Fig. 5)

\begin{tabular}{llll}
\hline $\begin{array}{l}\text { Universal Longitudinal } \\
\text { time }\end{array}$ & $\begin{array}{l}\text { Azimuthal } \\
\text { extent }\left( \pm 1^{\circ}\right) \\
\text { propagation } \\
\text { speed }\left( \pm 50 \mathrm{~m} \mathrm{~s}^{-1}\right)\end{array}$ & $\begin{array}{l}\text { Peak l-o-s } \\
\text { ionospheric flow } \\
\text { velocity }\left( \pm 100 \mathrm{~m} \mathrm{~s}^{-1}\right)\end{array}$ \\
\hline $22: 30$ & $7^{\circ}$ & -830 & 1200 \\
$22: 47$ & $5^{\circ}$ & -820 & 1200 \\
$22: 56$ & $5^{\circ}$ & -620 & 1200 \\
$23: 12$ & $6^{\circ}$ & -420 & 900 \\
$23: 26$ & $6^{\circ}$ & -1060 & 900 \\
\hline
\end{tabular}

\subsection{Statistical analysis of APVC observations}

Between the commissioning of the Finland radar (February 1995) and August 1998, CUTLASS has been operational for $\sim 29000 \mathrm{~h}$ and of these the radars have been operating in high-time resolution modes in the nightside for $\sim 1000 \mathrm{~h}$. However, of this dataset only $\sim 600 \mathrm{~h}$ contains useful backscatter data. During this period 25 examples of azimuthally propagating vortical currents similar to those discussed in the previous sections have been identified. From this it may be estimated that the average occurrence rate of APVC events is $\sim 1$ per day compared to an average substorm occurrence rate of $\sim 4$ per day reported by Borovsky et al. (1993), drawing on observations of over 1000 substorms. In addition, the difficulty in obtaining useful backscatter observations using $\mathrm{HF}$ instruments during substorms due to absorption as discussed by Milan et al. (1996) implies that the APVC occurrence rate is likely to be underestimated. When all the events are studied only $\sim 20 \%$ of the APVCs observed were isolated occurrences. During an interval of substorm activity it is much more common to observe a sequence of several APVCs. Of those events that occurred during a period in which more than one APVC was observed, $\sim 50 \%$ occurred within $30 \mathrm{~min}$ of the previous/subsequent APVC. By comparing the radar observation time of each event with the time of substorm onset/ intensification determined from ground magnetometer measurements, a histogram of occurrence relative to onset/intensification has been constructed (Fig. 9). Approximately $50 \%$ of APVCs observed occurred within the first hour after expansion phase onset and over $90 \%$ occurred within $2 \mathrm{~h}$. In only one case was an APVC observed in a quiet period preceding a substorm (the APVC leading the substorm by $16 \mathrm{~min}$ ). The mean magnitudes of several parameters associated with the

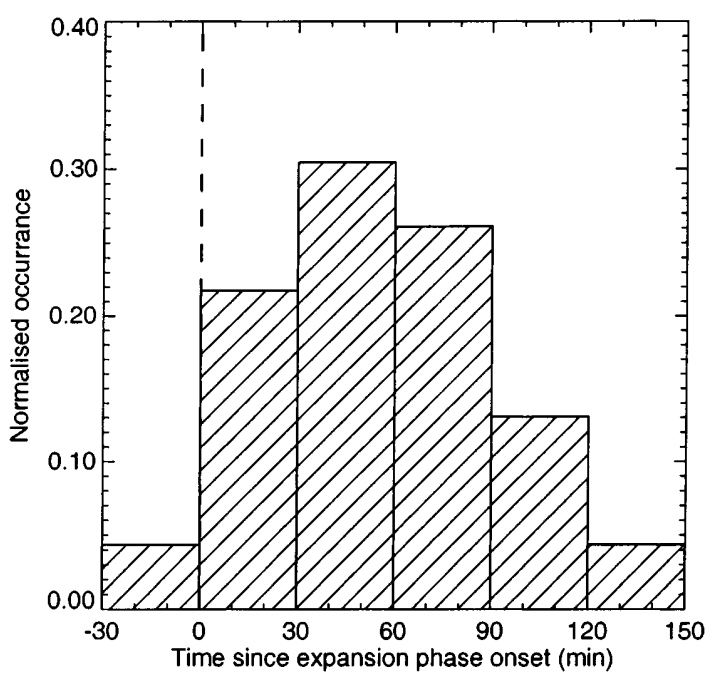

Fig. 9. A histogram presenting the normalised occurrence rate of azimuthally propagating vortical current systems observed by CUTLASS relative to magnetospheric substorm onset/intensification time. The dashed vertical line represents the moment of substorm onset 
APVC structures observed are presented in Table 2. In both interval 1 and interval 2 several APVCs were observed during the period of substorm activity. All of the flows interpreted as APVCs have been consistent with upward FACs and in no cases were the anticlockwise flows expected to be associated with downward FACs observed. Clearly, both upward and downward FACs are required in order to facilitate current closure through the ionosphere although the observations in this study yielded no information regarding the location of downward FACs with respect to the APVCs. However, it is possible that the highly structured electron precipitation associated with upward FACs is leading to a preferential selection of radar observations of upward FACs. Finally, the longitudinal separation of the observed location of each APVC event observed within the field-of-view of the radar from the region of expansion phase onset/intensification that has been associated with it has been plotted as a function of the azimuthal propagation velocity of that event (Fig. 10). Although there appears to be no direct relationship between longitudinal separation and propagation velocity there is an obvious trend that events that occur to the east of the onset region propagate eastward and vice-versa.

Table 2. Mean magnitudes of various characteristics of the 25 observed azimuthally propagating vortical current features

\begin{tabular}{ll}
\hline Parameter & Mean magnitude \\
\hline l-o-s convection velocity & $900 \mathrm{~m} \mathrm{~s}^{-1}$ \\
Azimuthal propagation velocity & $780 \mathrm{~m} \mathrm{~s}^{-1}$ \\
Spatial extent & $300 \mathrm{~km}(\mathrm{lat}) \times 400 \mathrm{~km}$ (lon) \\
Observed magnetic latitude & $65.5^{\circ}$ \\
$K_{P}$ index & 3 \\
\hline
\end{tabular}

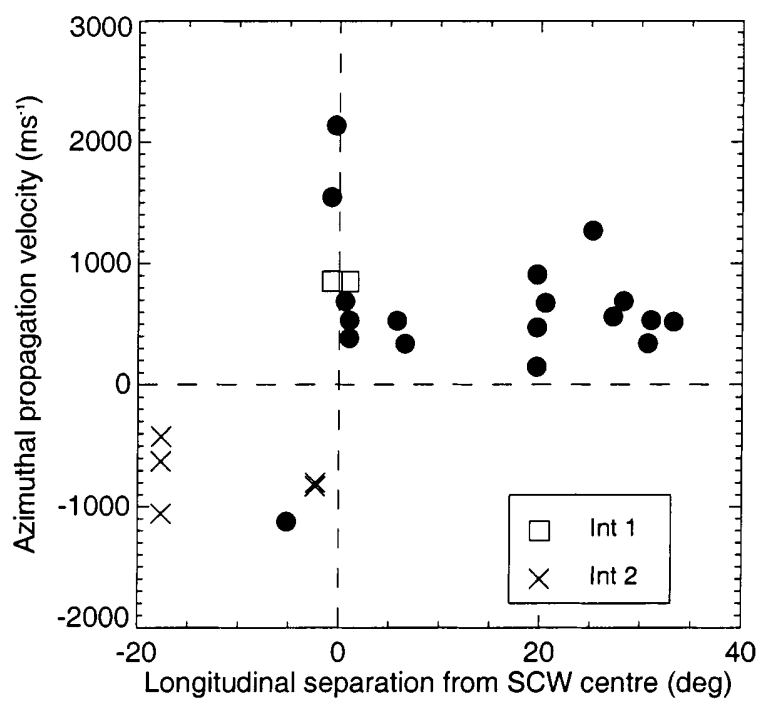

Fig. 10. The relationship between azimuthal propagation velocity of APVC events and the longitudinal separation from the region of substorm onset/intensification. Positive velocities indicate eastward propagation. The events discussed in the text are denoted by squares (interval 1) and crosses (interval 2)

\subsection{Azimuthally propagating vortical currents}

The CUTLASS observations presented indicate that APVC systems frequently propagate in an azimuthal direction away from the region of substorm onset/ intensification, outside of the substorm expansion bulge as presented in Fig. 11. However, their rapid propagation speeds and relatively short lifetimes within the f-o-v of any particular radar imply that high-time resolution observations ( $\sim$ few seconds) are required and these are not routinely implemented. From the small sample of observations of this phenomenon available it appears that APVCs propagate not only eastward, as first described by Yeoman and Lühr (1997), but also westward, in both cases moving away from the region of substorm onset. In this respect, the APVCs described are analogous to dayside travelling convection vortices (TCVs) which have been observed propagate westward through the morning sector at speeds of several kilometres per second (e.g. Glassmeier, 1992; Lühr et al., 1996). TCVs are usually described as pairs of antiparallel field-aligned currents closing in the ionosphere and are most commonly observed in the morning hours between 08-10 MLT. The study of TCVs by Lühr et al. (1993) included observations of the perturbations to equivalent currents derived from ground magnetometer data that are very similar to those presented in Figs. 3b and 7. The TCV twin-vortices observed in that study were inferred to have dimensions of $\sim 1000 \mathrm{~km}$ and $2000 \mathrm{~km}$ in the latitudinal and longitudinal directions respectively, somewhat larger than the APVC structures observed in the current study.

Yeoman et al. (1998) observed a series of APVCs propagating through the f-o-v of the CUTLASS Finland radar with durations $\sim 5 \mathrm{~min}$ and repetition period $\sim 8 \mathrm{~min}$. The overall morphology of the APVCs was very similar to the ionospheric twin-vortex signature that arises as a result of flux transfer events occurring at the dayside magnetopause (Lockwood et al., 1990) and it was proposed that source mechanism of these events may be transient reconnection at the near-Earth neutral line (NENL). It was further suggested that the azimuthal flows were the inner magnetosphere response to the

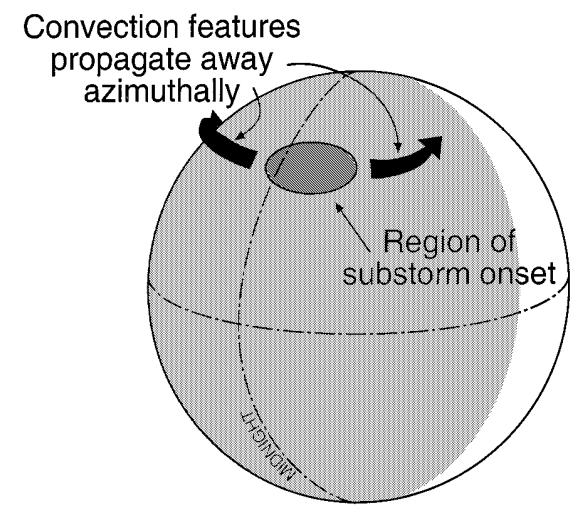

Fig. 11. A schematic representation of the propagation of the observed APVCs away from the region of substorm onset/intensification 
resulting Earthward plasma flows (often termed bursty bulk flows, e.g. Baumjohann et al., 1990) and this was supported by in-situ observations of the magnetosphere made by the Geotail spacecraft. If the APVCs studied here and by Yeoman et al. (1998) are signatures of transient reconnection at the NENL then observations up to $150 \mathrm{~min}$ after substorm onset are certainly unexpected and the single observation of an APVC prior to an onset remains unexplained. However, previous authors have observed delays $\sim 30$ min between substorm expansion phase onset and polar cap contraction, e.g. Lockwood and Cowley (1992) and Yeoman and Pinnock (1996).

By employing Viking images of the UV aurora Henderson et al. (1998) suggested that north-south aligned auroral structures could be the auroral signature of BBFs within the magnetotail whilst Lyons et al. (1999) reported a correlation between bursty flow activity in the magnetotail and the occurrence of auroral poleward boundary intensifications. There are many similarities between the events discussed in this study and those observed by Henderson et al. (1998) and Lyons et al. (1999), such as relationship to substorm phase, duration and repetition rate. However, neither author reported observing the significant systematic azimuthal motion that characterise APVCs. In order to make meaningful comparisons it will be necessary to combine two dimensional optical observations in conjunction with high-time resolution radar measurements of APVC structure. Unfortunately, the majority of intervals of high time resolution radar observations to date have occurred when conditions for optical observations were unsuitable and the optical characterisation of APVCs remains an area for future study.

\section{Conclusions}

During the period February 1995 to August 1998 the CUTLASS radars periodically operated in non-standard modes that provided enhanced resolution measurements of 1-o-s ionospheric Doppler velocities in specific beam directions whilst still taking sufficient measurements over the entire field-of-view in order to facilitate studies of ionospheric plasma flow velocities over $4 \times 10^{6} \mathrm{~km}^{2}$. When operating in such a mode short-lived $(\sim \min )$ regions of intense 1-o-s velocities $\left(\sim 500 \mathrm{~m} \mathrm{~s}^{-1}\right)$ were frequently observed to propagate in an almost azimuthal direction, often with a characteristic bipolar flow variation occurring over time scales of the order of minutes. The azimuthal propagation speed of these regions varied between $\sim 300-2000 \mathrm{~m} \mathrm{~s}^{-1}$ and the regions of intense flow are often associated with strong perturbations in the magnetic field recorded at the ground. Analysis indicates that these perturbations are the electric and magnetic field signatures of ionospheric Hall current vortices of scale sizes $\sim 400 \mathrm{~km}$, flowing around field aligned currents flowing out of the ionosphere.

By studying ground magnetometer data during the intervals in which azimuthally propagating vortical current (APVC) systems are observed it has been possible to determine the approximate location of any substorm activity during that interval. In all the cases studied, APVCs were observed within $150 \mathrm{~min}$ after a substorm expansion phase onset/intensification and in one case $18 \mathrm{~min}$ prior to onset. Furthermore, comparisons of the propagation velocity of APVCs and the location of substorm onset/intensification have revealed that although azimuthal propagation velocity does not appear to be directly related to the distance from the substorm onset, the direction of propagation is generally away from the ionospheric region of onset.

The conclusions drawn from the case study of a single APVC event by Yeoman and Lühr (1997) and the subsequent analysis of magnetotail structure during the same event (Yeoman et al., 1998) have been augmented by the inclusion of observations spanning more than three years. Yeoman et al. (1998) and Nakamura et al. (1999) have reported high-speed Earthward flows or BBFs in the magnetotail undergoing deceleration and azimuthal diversion in the near-Earth region. However, in order to more fully characterise any relationship with these flows and APVCs and allow comparisons to be made with other phenomena associated with BBFs such as north-south aligned auroral structures and poleward boundary intensifications it will be necessary to undertake a period of co-ordinated observations using not only high-time resolution ionospheric radars but optical instruments with a two-dimensional imaging capability and further in-situ spacecraft observations in the magnetosphere.

Acknowledgements. We would like to thank Børre Holmeslet, Tromsø Auroral Observatory, for providing the Jan Mayen magnetometer data, the Danish Meteorological Institute for supplying the Greenland magnetometer data and the Finnish Meteorological Institute for providing the IMAGE magnetometer data. The authors also thank A. Kadokura of the National Institute for Polar Research, Japan, for providing the Iceland magnetometer data and Dr I.R. Mann and Dr D.K. Milling for the SAMNET data. SAMNET is a PPARC National Facility deployed and operated by the University of York. The CUTLASS HF radars are deployed and operated by the University of Leicester, and are jointly funded by the UK Particle Physics and Astronomy Research Council (grant number PPA/R/R/1997/00256), the Finnish Meteorological Institute, and the Swedish Institute of Space Physics. This research has been carried out under a studentship awarded by PPARC.

The Editor in chief thanks P.E. Sandholt and another referee for their help in evaluating this paper.

\section{References}

Baumjohann, W., G. Paschmann, and H. Lühr, Characteristics of high-speed ion flows in the plasma sheet, J. Geophys. Res., 95, 3801-3809, 1990.

Borovsky, J. E., R. J. Nemzek, and R. D. Belian, The occurrence rate of magnetospheric-substorm onsets: random and periodic substorms, J. Geophys. Res., 98, 3807-3813, 1993.

Glassmeier, K.-H., Travelling magnetospheric convection twinvortices: observations and theory, Ann. Geophysicae, 10, 547$565,1992$.

Greenwald, R. A., K. B. Baker, J. R. Dudeney, M. Pinnock, T. B. Jones, E. C. Thomas, J.-P. Villain, J.-C. Cerisier, C. Senior, C. Hanuise, R. D. Hunsucker, G. Sofko, J. Koehler, 
E. Nielsen, R. Pellinen, A. D. M. Walker, N. Sato, and H. Yamagishi, Darn/SuperDARN: a global view of the dynamics of high-latitude convection, Space Sci. Rev., 71, 761-796, 1995.

Henderson, M. G., G. D. Reeves, and J. S. Murphree, Are northsouth aligned auroral structures an ionospheric manifestation of bursty bulk flows?, Geophys. Res. Lett., 25, 3737-3740, 1998.

Lester, M., W. J. Hughes, and H. J. Singer, Longitudinal structure in $\mathrm{Pi} 2$ pulsations and the substorm current wedge, J. Geophys. Res., 89, 5489-5494, 1984.

Lockwood, M, and S. W. H. Cowley, Ionospheric convection and the substorm cycle, Proc. Inst. Conf. On Substorms, ESA SP335, 99-109, 1992

Lockwood, M., S. W. H. Cowley, P. E. Sandholt, and R. P. Lepping, The ionospheric signatures of flux transfer events and solar wind dynamic pressure changes, J. Geophys. Res., 95, 17 113$17135,1990$.

Lühr, H., The IMAGE magnetometer network, STEP Int. Newsl., 4(10), 4-6, 1994.

Lühr, H., and K. Schlegel, Combined measurements of EISCAT and the EISCAT magnetometer cross to study $\Omega$ bands, J. Geophys. Res., 99, 8951-8959, 1994.

Lühr, H., W. Blawert, and H. Todd, Ionospheric plasma and current patterns of travelling convection vortices: a case study, J. Atmos. Terr. Phys., 55, 1717-1727, 1993.

Lühr, H., M. Lockwood, P. E. Sandholt, T. L. Hansen, and T. Moretto, Multi-instrument ground based observations of a travelling convection vortices event, Ann. Geophysicae, 14, 162181, 1996

Lyons, L. R., T. Nagai, G. T. Blanchard, J. C. Samson, T. Yamamoto, T. Mukai, A. Nishida, and S. Kokubun, Association between Geotail plasma flows and auroral poleward boundary intensifications observed by CANOPUS photometers, J. Geophys. Res., 104, 4485-4500, 1999.

Milan, S. E., T. B. Jones, M. Lester, E. M. Warrington, and G. D. Reeves, Substorm correlated absorption on a $3200 \mathrm{~km}$ trans-auroral HF propagation path, Ann. Geophysicae, 14, 182-190, 1996.

Morelli, J. P., R. J. Bunting, S. W. H. Cowley, C. J. Farrugia, M. P. Freeman, E. Friis-Christensen, G. O. L. Jones, M. Lester, R. V. Lewis, H. Lühr. D. Orr, M. Pinnock, G. D. Reeves, P. J. S. Williams, and T. K. Yeoman, Radar observations of auroral zone flows during a multiple onset substorm, Ann. Geophysicae, 13, 1144-1163, 1995.

Nakamura, R., G. Haerendel, W. Baumjohann, A. Vaivads, H. Kucharek, B. Klecker, E. Georgescu, J. Birn, L. M. Kistler, T. Mukai, S. Kokubun, P. Eglitis, L. A. Frank, and J. B. Sigwarth, Substorm observations in the early morning sector with Equator-S and Geotail, Ann. Geophysicae, 17, 1602-1610, 1999.

Pinnock, M., A. S. Rodger, J. R. Dudeney, F. Rich, and K. B. Baker, High spatial and temporal resolution observations of the ionospheric cusp, Ann. Geophysicae, 13, 919-925, 1995.

Rostoker, G., S.-I. Akasofu, J. Foster, R. A. Greenwald, Y. Kamide, K. Kawasaki, A. T. Y. Lui, R. L. McPherron, and C. T. Russell, Magnetospheric substorms - definitions and signatures, J. Geophys. Res., 85, 1663-1668, 1980.

Sato, N., H, Fukunishi, and T. Saemundsson, Operation plan for the Iceland-Syowa conjugate campaign in 1983-1985, Mem. Natl. Inst. Polar Res., 31, 169-179, 1984.

Wild, J. A., T. K. Yeoman, P. Eglitis, and H. J. Opgenoorth, Multiinstrument observations of the electric and magnetic field structure of omega bands, Ann. Geophysicae, 18, 99-110, 2000.

Wilhjelm, J., and E. Friis-Christensen, Electric fields and high latitude zonal currents induced by merging of field lines, Geophys. Pap., R-31, Danish Meteorological Institute, Charlottenlund, Denmark, 1976.

Yeoman, T. K., and M. Pinnock, The high-latitude convection response to an interval of substorm activity, Ann. Geophysicae, 14, 518-532, 1996.

Yeoman, T. K., and H. Lühr, CUTLASS/IMAGE observations of high-latitude convection features during substorms, Ann. Geophysicae, 15, 692-702, 1997.

Yeoman, T. K., and J. A. Wild, HF radar observations of azimuthally propagating transient convection features in the substorm electrojets, Proceedings of ICS-4, Eds. S. Kokubun and Y. Kamide, Kluwer Academic, Dordrecht, 1998.

Yeoman, T. K., D. K. Milling, and D. Orr, Pi2 pulsation polarisation patterns on the U.K. Sub-auroral Magnetometer Network (SAMNET), Planet. Space Sci., 38, 589-602, 1990.

Yeoman, T. K., T. Mukai, and T. Yamamoto, Simultaneous ionospheric and magnetospheric observations of azimuthally propagating transient features during substorms, Ann. Geophysicae, 16, 754-763, 1998. 